\title{
Notas sobre interação e socialização em Simmel: uma reflexão sobre educação e intolerância
}

\author{
Notes on interaction and socialization in Simmel: a reflection on education and intolerance
}

\section{Notas sobre interacción y socialización en Simmel: una reflexión sobre educación e intolerancia}

\author{
Carlos Alberto Barbosa
}

\section{Resumo}

Nos últimos anos de sua vida, Georg Simmel lecionou na Universidade de Estrasburgo, onde também foi responsável por ministrar palestras sobre pedagogia aos futuros licenciados, as Palestras sobre pedagogia escolar (Lectures on Schulpädagogik). Apesar de o tema da pedagogia não figurar entre seus interesses teóricos, que estavam mais orientados às interações e às formas de socialização, o que se depreende das discussões no entorno das palestras de Simmel é a relação que elas guardam com os processos de interação e socialização. Para ele, a formação (Bildung) não pode prescindir desses dois processos, sob pena de não se realizar na sua plenitude. Por sua vez, o processo de interação pressupõe a diferenciação entre os indivíduos de um mesmo círculo. As diferenças são o combustível que torna possível as interações e, consequentemente, a socialização e a formação (Bildung). Ao entender formação como um processo de socialização, e a diferenciação como elemento basilar de toda essa dinâmica, este artigo discute a necessidade de manutenção da diversidade de ideias e das diferenças nos ambientes de ensino, especialmente em um momento no qual a intolerância à diversidade e à pluralidade de ideias invade os mais variados espaços, inclusive os espaços de ensino e reflexão.

Palavras-chave: socialização; educação; interação; Georg Simmel.

\section{Abstract}

Throughout the last years of his life, Georg Simmel taught at the University of Strasbourg, where he was also responsible for giving lectures on pedagogy to future graduates, the Lectures on Schulpädagogik. Although the theme of pedagogy is not among their theoretical interests, which were more oriented towards interactions and forms of socialization, what emerges from the discussions surrounding Simmel's lectures is the relationship they have with the processes of interaction and socialization. For him, education (Bildung) cannot do without these two processes, under penalty of not being fully realized. In turn, the interaction process presupposes the differentiation between individuals in the same circle. Differences are the fuel that makes interactions possible, and therefore socialization and the education (Bildung). When understanding training as a socialization process, and differentiation as a basic element of all this dynamic, this article discusses the need to maintain the diversity of ideas and differences in teaching environments, especially at a time when the practice of intolerance to diversity and plurality of ideas invades a diversity of environments, including those dedicated to teaching and reflection.

Keywords: socialization; education; interaction; Georg Simmel.

Recebido em: 30/07/2020 - Aprovado em: 15/04/2021

http://dx.doi.org/10.5335/rep.v28i1.11489

Pós-doutorando da Faculdade de Educação da USP, com pesquisa sobre socialização em Georg Simmel. Doutor em Design pela Universidade Anhembi Morumbi. Mestre em Filosofia pela PUC-SP. Pesquisador do Grupo de Pesquisa GPS Práticas de Socialização Contemporâneas. Orcid: https://orcid.org/0000-0002-8477-4673. E-mail: carlosalberto.barbosa@ gmail.com 


\section{Resumen}

En los últimos años de su vida, Georg Simmel enseñó en la Universidad de Estrasburgo, donde también fue responsable de dar conferencias sobre pedagogía a futuros graduados (Lectures on Schulpädagogik). Aunque el tema de la pedagogía no se encuentra entre sus intereses teóricos, que estaban más orientados hacia las interacciones y formas de socialización, lo que surge de las discusiones que rodean las conferencias de Simmel es la relación que tienen con los procesos de interacción y socialización. Para él, la fromación (Bildung) no puede prescindir de estos dos procesos, bajo pena de no realizarse plenamente. A su vez, el proceso de interacción presupone la diferenciación entre individuos en el mismo círculo. Las diferencias son el combustible que hace posibles las interacciones y, por lo tanto, la socialización y la formación (Bildung). Al entender la capacitación como un proceso de socialización y la diferenciación como un elemento básico de toda esta dinámica, este artículo analiza la necesidad de mantener la diversidad de ideas y las diferencias en los entornos de enseñanza, especialmente en un momento en que la intolerancia a la diversidad y la pluralidad de ideas invade espacios más variados, incluyendo espacios de enseñanza y reflexión.

Palabras clave: socialización; educación; interacción; Georg Simmel.

\section{Introdução}

A realidade empírica, porém, continua ali, incontornável, e deixa estupefatos os que não souberam mudar a tempo de ideias. Quanto aos outros, tão próximos da farsa e da hipocrisia, empregam-se, com constância, a deturpar o sentido do acontecimento para fazê-lo entrar, pela força, no prêt-à-porter de uma verdade dogmática elaborada pela circunstância (MAFFESOLI, 2011, p. 15).

Em tempos de pandemia, para além do coronavírus, invisível e que não respeita fronteiras, um outro vírus nefasto está em circulação, e não é de hoje. Este outro vírus, a exemplo do coronavírus, também é pandêmico, cruza fronteiras e se estabelece em diferentes regiões do planeta. Trata-se do vírus da intolerância, que não admite as diferenças e olha o não idêntico a si mesmo como suspeito e inimigo a ser vencido. $O$ mundo ideal do vírus da intolerância é uma sociedade sem oposição de ideias, sem debates e sem diversidade de pensamentos e opiniões. No Brasil, entre tantas vítimas do vírus da intolerância, a educação passou a ser dos seus alvos preferidos nos últimos tempos.

A despeito dos preceitos constitucionais de "[...] igualdade de condições para acesso e permanência na escola" e do "[...] pluralismo de ideias e de concepções pedagógicas [...]" (BRASIL, 1988, não paginado), o que se tem testemunhado são tentativas de barrar o pensamento diverso nos ambientes de ensino, sob os mais variados pretextos. Ora se observa um discurso incentivando o ensino domiciliar, o chamado homeschooling, que pode levar à exclusão de crianças de uma experiência de convívio com as diferenças e com a diversidade de pensamentos, ora são evidenciadas tentativas que visam dificultar o acesso à universidade e a cursos de 
pós-graduação de minorias e populações em condições econômicas menos favorecidas. Não cabe a este artigo uma discussão sobre as motivações que levaram a tais tentativas de ataque ao ensino, tentativas que têm sido barradas pelos poderes Legislativo e Judiciário. O risco de especular sobre tais motivações poderia fazer com que a questão de fundo sobre uma educação para a autonomia venha a se perder. Igualmente não é propósito desse artigo proceder uma discussão acerca das minúcias jurídicas e dos aspectos constitucionais ou inconstitucionais que rodeiam esses ataques. Ao contrário, vale lembrar as palavras de Max Weber (1979, p. 252) sobre a necessidade de "[...] precaver-nos contra a crença de que os princípios 'democráticos' de justiça são idênticos à 'adjudicação racional”, e fazer valer tais princípios a partir de uma discussão sobre o mal que a intolerância causa no processo de formação. O que este artigo propõe é uma reflexão sobre a importância da diferença e da diversidade na educação, e seu argumento central está pautado no reconhecimento dessa importância.

Para auxiliar nessa reflexão, o artigo parte de alguns comentadores que abordam a temática da educação nos textos de Simmel, os quais tomam as relações entre diferenciação e interação, bem como suas implicações nos processos de individualização e socialização. A diferenciação é entendida como pressuposto dos processos de interação e socialização, o que permite centrar o olhar sobre os espaços de educação e formação como espaços de interação, desde que esses espaços sejam provocados pelo estranhamento das diferenciações, sejam eles os espaços tradicionais de salas de aula ou os espaços onde ocorrem diferentes interações e socializações, como, por exemplo, os ambientes de difusão cultural.

No final do século XIX e início do século XX, Simmel questionou o conhecimento consolidado na forma de um pensamento totalizante, apontando para os problemas advindos de uma teoria ensimesmada, alheia à realidade circundante. Nesse sentido, o pensamento simmeliano pode ser um ponto de apoio importante na discussão de temas caros ao presente, tais como os já citados conceitos de interação e socialização, participantes na construção da individualidade, da subjetividade e da sociedade. Sociedade que, nas palavras de Simmel (2006, p. 18), "[...] não é, sobretudo, uma substância, algo que seja concreto para si mesmo".

As preocupações teóricas levadas a cabo por Simmel ao refletir sobre os fundamentos e condições de sociabilidade (Gesselingkeit) de uma sociedade (Gesellschaft) que só podem existir em meio aos processos de interação (Wechselwirkung) e socialização (Vergesellschaftung) ${ }^{1}$, estabelecem estreita relação com processos de formação (Bildung $)^{2}$, os quais não podem prescindir das diferenciações entre indi- 
víduos que participam de um mesmo círculo. Dessa forma, entende-se que qualquer movimento na direção de fazer perseverar a intolerância à diversidade de ideias acaba por tornar-se uma tentativa de apequenar os processos de socialização e, consequentemente, da própria formação.

\section{Sala de aula e espaço de interação}

Em 2019, o Simmel Studies ${ }^{3}$ dedicou um dossiê à discussão do papel de Georg Simmel como educador. Naquele dossiê, intitulado Simmel as Educator, o ponto de partida dos artigos foram as Palestras sobre pedagogia escolar (Lectures on Schulpädagogik), originadas de uma série de anotações de aulas feitas por de Simmel, que foram recolhidas, organizadas e publicadas postumamente pelo seu assistente (AMAT; D'ANDREA, 2019). Embora as aulas de Simmel tenham sido um enorme sucesso entre os alunos, em especial no período em que ele lecionou em Berlim ${ }^{4}$, os temas ligados à pedagogia não foram parte central dos seus interesses teóricos (D'ANDREA, 2019; GONON, 2019; MÜLLER, 2019; VERNIK, 2019). A realização das Palestras sobre pedagogia escolar não foi de sua livre escolha, mas fruto de uma tarefa compulsória de ministrar aulas sobre procedimentos pedagógicos e didática para alunos da Universidade de Estrasburgo, onde ele lecionou filosofia por um curto período, em seus últimos anos de vida (GONON, 2019).

$\mathrm{O}$ fato de a pedagogia não ser um dos destaques entre os muitos interesses de Simmel, não foi o único motivo pelo qual o tema não ocupou parte significativa do seu tempo e da sua produção intelectual. Além dos diversos outros interesses teóricos que atraíram sua atenção, existiam também questões ligadas à organização das disciplinas acadêmicas do seu tempo, que fizeram com que as discussões sobre educação não ocupassem lugar de destaque no cenário teórico simmeliano. $\mathrm{Na}$ Alemanha do início do século XX, a própria pedagogia não havia se firmado ainda como disciplina autônoma, o que só ocorreu em meados daquele século. $\mathrm{O}$ período também coincide com o momento em que ganharam força na Alemanha as discussões sobre a construção da sociologia como disciplina (GONON, 2019). Simmel estava especialmente dedicado a essa segunda causa, tendo sido ele um dos organizadores dos encontros da Sociedade Alemão para a Sociologia (Deutsche Gegesellschft für Soziologie) (GONON, 2019).

Se, por um lado, o tema da pedagogia não foi central na sua produção, de outro, os textos do dossiê demonstram como suas palestras sobre educação guardam relação com outras questões teóricas, essas sim mais ao seu gosto, tais como ques- 
tões ligadas à interação e à socialização. Simmel entendia que a própria aula constituía “[...] um tipo de relação, uma troca de efeito recíproco (Wechselwirkung) entre o professor e sua audiência"5 (VERNIK, 2019, p. 67, tradução nossa). Um exemplo da intensidade dessa troca de efeito recíproco em suas aulas pode ser percebido no depoimento de Emil Ludwig, quando lamenta a saída de Simmel da Universidade de Berlim, em 1914, para assumir a cátedra em Estrasburgo:

Nós não poderemos mais ouvi-lo em Berlim, nós não o veremos mais: e isto é triste porque [...] só se pode compreendê-lo inteiramente, não quando se o lê, mas só quando se o ouve, se o vê [...] ele pensa de modo visível [...] ouvir significa então alguma coisa como: construir em conjunto. Na verdade não se ouve: antes se pensa, se pensa em conjunto (LUDWIG apud WAIZBORT, 2013, p. 573).

Essa relação recíproca, ou interação (Wechselwirkung), tem papel importante no pensamento simmeliano, especialmente no que diz respeito ao entendimento das dinâmicas que envolvem diferenciação e os processos de socialização ${ }^{6}$. Como lembra o próprio Vernik (2019, p. 67, tradução nossa), o conceito de interação é central na "[...] sociologia relacional de Simmel [...] bem como no seu pensamento global, incluindo seu propósito pedagógico”. Segundo Häußling (2018, p. 588 apud VERNIK, 2019, p. 67, tradução nossa), interação:

Significa que um ator social (um indivíduo, um grupo, ou uma configuração social) está fazendo, percebendo, ou esperando, tem impacto no que outro ator social está fazendo, percebendo ou esperando. Toda interação (Wechselwirkung), apesar do seu conteúdo livremente selecionado, deve selecionar formas determinadas de socialização (Vergesellschaftung), a fim de se articular "socialmente". A Wechselwirkung não seleciona as formas arbitrariamente, mas a partir de uma estrutura geral dinâmica, a qual Simmel conceitua como socialização.

O dinamismo dessa estrutura apontado por Häußling é chave no conceito simmeliano de interação e de socialização. O dinamismo faz referência ao movimento que ocorre em toda a estrutura, em um fluxo incessante, no qual:

[...] os indivíduos estão ligados uns aos outros pela influência mútua que exercem entre si e pela determinação recíproca que exercem uns sobre os outros. A sociedade é também algo funcional, algo que os indivíduos fazem e sofrem ao mesmo tempo, e que, de acordo com esse caráter fundamental, não se deveria falar de sociedade [Gesellschaft], mas de sociação [Vergesellschaftung]. Sociedade é, assim, somente um nome para um círculo de indivíduos que estão, de uma maneira determinada, ligados uns aos outros por efeito das relações mútuas, e que por isso podem ser caracterizados como uma unidade - da mesma maneira que se considera uma unidade um sistema de massas corporais que, em seu comportamento, se determinam plenamente por meio de suas influências recíprocas (SIMMEL, 2006, pp. 17-18, grifo nosso). 
A ideia de sociedade para Simmel é uma abstração conceitual que torna manifesta uma unidade que só se realiza na instabilidade das relações mútuas, como um corpo que põe em movimento uma bicicleta. O conjunto ciclista e bicicleta só se equilibra a partir da dinâmica das diferentes partes do corpo humano sobre um outro corpo externo a ele que é a bicicleta. É a dinâmica das diferentes partes do corpo humano que dá movimento à bicicleta, e a torna efetivamente funcional. Nesse sentido, a ideia de sociedade é como uma fotografia que tenta retratar em um instantâneo o intenso movimento que o antecede, como a imagem captada de um ciclista sobre sua bicicleta, que congela as diferentes partes do corpo do ciclista em movimentos coordenados, e a própria dinâmica do conjunto para forjar uma unidade que ocorre somente na mudança e instabilidade entre as partes do corpo do ciclista, e do conjunto envolvendo essa totalidade móvel que contém o ciclista e a bicicleta. Escavar e revelar o movimento que está na origem desse instantâneo é parte do interesse de Simmel, que discute como são possíveis a individualidade e a própria sociedade (MÜLLER; CAVALLI; FERRARA, 2018). Simmel realiza esse instantâneo a partir de observações da vida cotidiana expostas em textos em um estilo ensaístico (WAIZBORT, 2013; VANDENBERGHE, 2018), provocador, e que busca nas experiências do mundo os indícios de generalizações das formas de socialização. O cotidiano é fonte de matéria-prima para Simmel, que "[...] não pôde ignorar a multiplicação dos microgrupos que, apesar de apenas nascentes, vinham sendo difundidos nas metrópoles modernas" (MAFFESOLI, 2014, p. 245). A força de sua microssociologia está presente na maneira aguçada como ele retira da vida comum e dos acontecimentos prosaicos e inesperados os elementos para reflexão teórica, como, por exemplo, a moldura de um quadro (SIMMEL, 2016). Simmel (2006, p. 18) faz dessas peculiares observações de campo os eventos reveladores de uma sociedade, a qual, conforme já citado, "[...]os indivíduos fazem e sofrem ao mesmo tempo[...]".

Essa "estrutura geral dinâmica" que caracteriza a socialização, bem como a condição peculiar do indivíduo diante de uma sociedade que ele "faz e sofre ao mesmo tempo", revelam que a interação ocorre sempre sob um sistema instável, ou melhor, que ela é parte de uma dinâmica que visa o aspecto unitário de um sistema que é, por força da própria interação que o constitui, instável. Um sistema que se vê às voltas com indivíduos constantemente trocando de posições, intercambiando ideias e valores (D’ANDREA, 2019). A visão de Simmel sobre a dinâmica que envolve o processo de socialização e formação da sociedade implica em uma perspectiva crítica de uma modernidade identificada com a possibilidade de apreensão 
da totalidade. Uma Modernidade Iluminista7, que não se dá conta do fato "[...] de que todo esse processo que leva a um equilíbrio estático, onde tudo permanece mais ou menos o mesmo, é pelo menos ingênua, pois deixa de levar em conta o dinamismo essencial da realidade [...]”' (D’ANDREA, 2019, p. 56, tradução nossa). Para o pensamento simmeliano, crítico da estabilidade que essa visão ingênua que a Modernidade Iluminista pretende cravar,

Em vez de uma abordagem estática, deve-se imaginar um relacionamento dinâmico em que todos os elementos deem sentido uns aos outros, sem que seja necessária a existência do todo, que muda e permanece o mesmo, em uma espécie de dança em espiral que pode até ser pensada como a imagem da vida (D’ANDREA, 2019, p. 57, tradução nossa).

No limite, a ingenuidade da ideia da possibilidade de uma apreensão do todo acaba por desconsiderar as partes, uma vez que essa apreensão tende a imobilizar as interações movidas pelas diferenciações entre indivíduos, e os próprios fenômenos observados, que passam de móveis e instáveis para a condição de estáticos. $\mathrm{Na}$ Modernidade Iluminista, o instante fotográfico que congela a realidade passa a ser, ele mesmo, o objeto de interesse, deixando em segundo plano o processo que ele pretendia revelar.

Ao final, a tentativa de apreensão do todo acaba por neutralizar a própria individualidade e a subjetividade, quando, ao contrário disso, a interação deveria “[...] ser interpretada não apenas como a fonte de uma rede relacional fundamental, mas como um movimento criativo através do qual a substância subjetiva surge e se desenvolve" (D'ANDREA, 2019, p. 57, tradução nossa).

\section{Diferenciação e socialização}

Parece ser claro até aqui, e nunca é demais repetir, que a dinâmica observada no processo de socialização decorre da interação do indivíduo com um outro não semelhante a ele. São as diferenciações entre os membros de um mesmo círculo social que impulsionam de maneira decisiva as interações, e sustentam os processos de individualização. Para que a bicicleta ande, as partes do corpo do ciclista devem guardar as diferenças entre si, revelando as distintas funcionalidades de cada uma delas, assim como o ciclista, na sua totalidade de diferenças, deve se identificar como um corpo que se distingue da bicicleta. Assim, para Simmel (2006, p. 45-46), as diferenciações são elementos fundamentais na dinâmica social: 
Seja como fato ou como tendência, a semelhança com os outros não tem menos importância que a diferença com relação aos demais; semelhança e diferença são, de múltiplas maneiras, os grandes princípios de todo desenvolvimento interno e externo. Desse modo, a história da cultura da humanidade deve ser apreendida pura e simplesmente como a história da luta e das tentativas de conciliação entre esses dois princípios. Bastaria dizer que, para a ação no âmbito das relações do indivíduo, a diferença perante outros indivíduos é muito mais importante que a semelhança entre eles. A diferenciação perante outros seres é o que incentiva e determina em grande parte a nossa atividade.

Para Vernik (2017), ao colocar a diferenciação como dinâmica presente em um círculo de indivíduos, Simmel também traz à tona a condição que permite a individualização e a existência de uma relação direta entre o número de círculos aos quais o indivíduo pertence e as oportunidades de individualização. Partindo desta observação, pode-se entender que o processo de formação da individualidade demanda dois níveis distintos de diferenciação. O primeiro deles é interno a um círculo de indivíduos, e diz respeito às diferenças entre os indivíduos dentro desse mesmo círculo. $\mathrm{O}$ segundo nível de diferenciação diz respeito à mobilidade entre os diferentes círculos frequentados por um indivíduo. Quanto maior o número de círculos frequentados por ele, maior as chances de individualização, ou ainda, a individualização pode ocorrer em maior grau de dessemelhança em relação aos demais indivíduos. Por fim, há de se considerar que o trânsito entre diferentes círculos é facilitado quando cada um dos círculos é composto por integrantes de outros tantos círculos, que fornecem condições específicas de interação entre os distintos círculos por onde esses indivíduos transitam, levando novos integrantes para alimentar as diferenciações em cada um deles. Dito de outra forma, quanto maior o número de círculos frequentados pelo indivíduo, e mais frequente for o seu trânsito entre os diferentes círculos marcados por dessemelhanças, em tese, maior serão as chances de promoção de interações a partir de movimentos de aproximação e separação entre indivíduos e círculos distintos, e maiores as possibilidades de individualização. Este trânsito e interação entre indivíduos que guardam diferenciações entre si, auxiliam na formação de um cenário que propicia a construção da identidade por semelhança e diferenciação. Tal circunstância oferece parâmetros para que o indivíduo seja submetido em menor escala ao crivo de aprovação, ou rejeição, de determinado círculo específico, tendo em vista a diversidade de visão de mundo que o indivíduo tem acesso ao transitar entre diferentes círculos.

Portanto, desligar-se dos círculos ou evitar que as diferenciações ocorram no interior de cada círculo não parecem ser bons caminhos para a individualização e a autonomia. Ao contrário, o pertencimento a um ou mais círculos nos quais o 
convívio entre semelhantes e dessemelhantes é uma realidade, e o trânsito entre diversos círculos, nos quais as dessemelhanças estejam presentes, é o que garante minimamente os processos de interação, individualização e da elaboração de uma subjetividade, levando a uma aproximação da experiência da autonomia, mesmo que instável e transitória.

\section{Diferenciação e formação (Bildung)}

Todo movimento do espírito que caminha na direção oposta do reconhecimento das diferenciações e de suas provocações, acaba por percorrer um caminho de apequenamento dos processos de individualização. A individualização não deve confundir-se com o pensamento ensimesmado e o isolamento. Simmel, ao considerar a sala de aula como espaço de interação (VERNIK, 2019), entende que naquele microcosmo transitam partes de diferentes círculos, envolvendo indivíduos que se relacionam pelas diferenças e semelhanças, e é a partir dessas diferenças e semelhanças que os processos de individualização ocorrem. A mobilidade entre diferentes círculos promove um maior número de interações e produz diversidade de processos de socialização, que são condições para a individualização e, consequentemente, para a ampliação da possibilidade de autonomia do indivíduo. $\mathrm{O}$ espaço da sala de aula, ao expor o indivíduo às diferenças e ao trânsito entre círculos, abriga essa diversidade e promove socializações. Não se trata unicamente de aceitar as diferenças e o multiculturalismo de forma normatizada, mas como uma perspectiva epistemológica. Trata-se de abraçar a mudança que transforma a consciência, como aponta Bell Hooks (2017).

Esse espaço que promove o encontro das diferenças e da interação, é também o espaço que instiga a Bildung, como formação mais plena e livre, desde que, segundo Simmel, se observe a dupla finalidade da sala de aula, como a abordagem de conteúdos funcionais e o fortalecimento e elevação moral do aluno (GOLDMAN, 2013). A questão da moral enunciada por Goldman marca o desdobramento da ordem do subjetivo que passa a constituir uma realidade objetiva ao agir sobre o mundo em um movimento ético-estético (SIMMEL, 2004 apud MÜLLER, 2019), e se confronta com a subjetividade dos outros indivíduos.

Berger e Luckmann (1985) apontam a realidade social como uma dialética marcada por três momentos: exteriorização, objetivação e interiorização. A exteriorização corresponde ao plano estético que comunica a subjetividade de um indivíduo. Ao depositar essa exterioridade no mundo, na forma de um objeto (concreto 
ou abstrato), ganha espaço o processo de objetivação, como processo portador da subjetividade exteriorizada, que pode ser tomada como fenômeno por outros indivíduos. Por fim, a interiorização ocorre quando o indivíduo faz o caminho contrário, e recolhe do mundo os objetos carregados de sentidos, fruto das subjetivações de outrem.

Embora os autores marquem que não existe uma sequência linear e cronológica nesse processo, visto que os três momentos estão contidos na realidade social observável, didaticamente eles apontam que:

O ponto inicial deste processo é a interiorização, a saber a apreensão ou interpretação imediata de um acontecimento objetivo como dotado de sentido, isto é, como manifestação de processos subjetivos de outrem, que desta maneira torna-se subjetivamente significativo para mim (BERGER; LUCKMANN, 1985, p. 174).

A estrutura traçada por Berger e Luckmann (1985) apresenta nuances de uma síntese que, se não se realizou na sua plenitude, ao menos aponta para a sociedade como síntese de uma dialética clássica, segundo os caminhos weberianos. Nesse ponto, a perspectiva de Simmel sobre a dinâmica de uma dialética do social guarda certa distância. Para ele, a instabilidade do sistema é a regra, "[...] que se resume da melhor maneira através do (meta)conceito do dualismo, da dualidade em interação ou da dialética sem síntese" (VANDENBERGHE, 2018, p. 53). Um sistema instável no qual "É a ação recíproca entre os indivíduos, e não a ação individual ou a totalidade social que é a unidade elementar da sociologia simmeliana" (VANDENBERGHE, 2018, p. 100), e "O que interessa à Simmel é o jogo das interações como substrato vivo do social, como cadinho da sociedade" (VANDENBERGHE, 2018, p. 94). Essa dialética sem síntese vai ao encontro da experiência vital da qual fala Paulo Freire (2020, p. 50), ao afirmar que: “Onde há vida, há inacabamento”, e “[...] o inacabamento de que nos tornamos conscientes nos fez éticos” (2020, p. 58).

De qualquer maneira, o didatismo do esquema de Berger e Luckmann apontam, mais uma vez, para a importância do reconhecimento do outro como diferente, como condição para que o próprio mundo concreto adquira sentido, ou múltiplos sentidos. Desde o plano estético de uma subjetividade que encarna no mundo na forma de objetos a serem tomados por outros indivíduos como fenômenos ricos de sentidos, o que é revelado nesse jogo dialético é, por um lado, uma ideia de sociedade como uma estabilidade fugidia, e, por outro lado, o indivíduo que se assoma do mundo, tomando fenomenologicamente os objetos como a encarnação de significados a serem desvelados, ao mesmo tempo em que ele, indivíduo, realiza sua individualidade. 
Da mesma forma, Simmel observou que "A Bildung, no sentido clássico alemão, é alcançada se as coisas não são apenas conhecidas em si mesmas [...]” (MÜLLER, 2019, p. 34), mas uma formação que visa o espírito, e se desdobra novamente na realidade concreta circundante, dando seguimento a uma relação conflituosa entre sociedade e indivíduo, conflito que "[...] prossegue no próprio indivíduo como luta entre partes de sua essência" (SIMMEL, 2006, p. 84). Ou ainda, a Bildung é:

[...] o fortalecimento, o refinamento, a amplitude de oscilação do espírito, sua elevação ético-estética, o direcionamento da alma ao encontro do espiritual e do valioso. Bildung é a síntese desses dois objetivos. Porque Bildung não é o mero conteúdo cognoscível, nem o mero ser como a constituição de uma alma sem conteúdo (SIMMEL, 2004, p. 356 apud MÜLLER, 2019, p. 34-35).

Mas essa amplitude de oscilação do espírito se vê ameaçada, conforme aponta Simmel (2013, p. 110), em A crise da cultura, quando: "As vivências atuais parecem intervir com significado mais tangível em outro desenvolvimento da cultura, a elevação de meros meios a fins em si”. A consequência dessa troca de meio pelo fim é a interrupção do processo dialético, quando a objetivação deixa de significar a subjetividade que lhe deu origem, ou deixa de ser decodificada ou significada pela subjetividade de outrem que a recolhe no fenômeno. O objeto então se cristaliza como coisa no mundo, e deixa de ser um "conteúdo cognoscível" para ser tomado por uma "alma sem conteúdo".

O espaço da sala de aula, como espaço de interação, conforme apontou Simmel (VERNIK, 2019), é um antídoto para este mal que interrompe a "amplitude de oscilação do espírito" presente na Bildung. Bildung entendida não como formação no sentido estritamente técnico, ou de treinamento, o que foi alvo de críticas por parte de Simmel (NORDENBO, 2002; D’ANDREA, 2019), mas Bildung como formação mais ampla, como um "refinamento" do espírito, conforme apontado por Simmel, o que pode ser observado também na mudança de percepção dos espaços destinados aos processos de socialização e de formação.

A Bildung, como formação mais ampla, foi acompanhada também por uma mudança sobre o entendimento dos espaços exclusivos dedicados ao ensino formal, reconhecendo-se que "[...] as ações educativas não se realizam apenas nos espaços institucionais tradicionais" (SETTON, 2005, p. 346), mas nos círculos onde o consumo da vida objetivada possa se converter em processos de subjetivação, tal como é oportunizado nos encontros de diferentes experiências e do choque da vida interna subjetiva com a realidade externa, em uma variada gama de espaços de socialização. A sala de aula pode ser um desses espaços nos quais os choques e as 
interações se realizam, e onde as diferenciações estão presentes e os processos de socialização ocorrem, da mesma maneira como também ocorrem nos espaços culturais (SETTON, 2005; SETTON; OLIVEIRA, 2017). Todos esses cenários oferecem as condições de sociabilidade que favorecem a produção da cultura "[...] na medida em que há a aproximação de dois elementos: a alma subjetiva e o produto espiritual objetivo; sendo que nenhum deles a contém por si” (SIMMEL, 2014, p. 81). A preocupação de Simmel (2013, p. 87), segundo a qual "[...] os homens somente num grau menor estão em condições de extrair, a partir da consumação dos objetos, uma consumação da vida subjetiva", pode ser aplacada, ao menos em parte, quando o conjunto de diferentes círculos e o trânsito dos indivíduos entre esses círculos ocorre, dando oportunidade e estímulo para que a conversão do objeto consumido torne-se consumação de vida subjetiva, e a síntese provisória entre o "conteúdo cognoscível" e a alma aconteça. O impedimento do acesso às diferenças nos espaços onde as interações ocorrem, sejam salas de aula, espaços de lazer ou equipamentos culturais, é danoso tanto para aquele que é impedido de frequentar esses ambientes, quanto aos que lá já se encontram isolados e privados de provocações, estímulos e interações que a diversidade pode promover. Tanto aqueles cujo acesso às diferenciações é obstruído, quanto os que permanecem isolados em bolhas culturais, os quais enfrentarão dificuldades em extrair "da consumação de objetos, uma consumação da vida subjetiva".

Hoje, mais do que nunca, a recuperação da Bildung implica em dar voz à dicotomia indivíduo e sociedade, vida interna e externa (D'ANDREA, 2019). Ao discorrer sobre as implicações entre educação e cultura em Simmel, Goldman (2013, p. 28) lembra que: "Os conflitos mais delicados da vida moderna advêm da resistência oferecida pelo indivíduo de ser nivelado, e da aspiração do homem em preservar sua peculiaridade e autonomia diante da sociedade", reeditando "o conflito entre a sociedade e o indivíduo [...]" (SIMMEL, 2006, p. 84). Mas esse conflito não se resolve cedendo ao nivelamento ou abandonando a aspiração à peculiaridade e à autonomia. Ao contrário, o fundamental é entender que a manutenção, quer da sociedade, quer do indivíduo peculiar e autônomo, depende da clareza quanto ao fato de que "A contraposição entre o todo [...] e a parte [...] não se resolve a princípio: não se constrói uma casa a partir das casas, e sim a partir de pedras formadas; nenhuma árvore cresce a partir de árvores, e sim a partir de células diferentes" (SIMMEL, 2006, p. 84). Para que o indivíduo note que sua peculiaridade e autonomia dependem das subjetivações e, portanto, dos dessemelhantes a ele, é imprescindível que 
a cultura se apresente sempre no plural, promovendo o reconhecimento das diferenças para que elas sejam objeto de "consumação da vida subjetiva".

\section{Conclusão}

A partir da importância dos processos de interação e socialização para a formação (Bildung), e tendo em vista a diferenciação como elemento fundamental para tais processos, é possível afirmar que qualquer tentativa de barrar as diferenças nos ambientes de debates e discussão de ideias incorrerão no solapamento dos processos de interação e socialização, e, consequentemente, na formação (Bildung). Passar ao largo do reconhecimento e da tolerância das diferenças, sejam quais forem as justificativas para tal, acabam por promover uma formação sem a amplitude necessária para a constituição de forças mobilizadoras que garantam a autonomia do sujeito, o que um objetivo da educação.

O que a intolerância às diferenças e a aversão à diversidade de pensamentos promovem, por certo, é a dificuldade dos processos de interação e, consequentemente, das possibilidades do indivíduo se relacionar com as diferentes subjetividades, que são matéria-prima necessária para a exteriorização, objetivação e interiorização, gerando novos processos de subjetivação, que mais uma vez se lançará ao mundo. A interrupção do processo vivo que dá origem ao social a partir de uma intensa dinâmica de interações, não mata apenas as ideias, mas também a própria essência da formação e da vida social. Para ir além do plano jurídico-constitucional que garante o acesso à escola e o pluralismo de ideias, uma sociedade saudável deve manter o convívio entre as diferenças, que é tão vital para a sociedade quanto $o$ ato de pedalar é vital para manter a bicicleta em equilíbrio dinâmico.

\section{Notas}

1 Os termos em alemão Wechselwirkung, Vergesellschaftung, Gesellschaft e Geselligkeit são vertidos neste texto por interação, socialização, sociedade e sociabilidade, respectivamente. Apesar de reconhecer a validade das discussões sobre a melhor forma de verter esses termos para o português, em especial as variantes de Vergesellschaftung, optou-se por socialização para este último, mantendo a palavra sociação nos casos das citações literais de obras em português que privilegiam essa forma de escrita. A anotação desses termos no idioma alemão só será mantida quando a citação literal do texto utilizado optar por manter o termo no original em alemão. Este é o caso de alguns dos textos do periódico Simmel Studies, presentes em citações neste artigo.

2 Sobre a Bildung, ver artigo de Sven Erik Nordenbo, Bildung and the Thinking of Bildung, citado neste artigo e indicado nas referências, no qual o autor traça um histórico do termo, desde o sentido de uma educação técnica e funcionalista, criticada por Simmel, até a recuperação do seu uso como formação para além dos conteúdos utilitários. Nordenbo também recupera a etimologia da palavra, verificando seu sen- 
tido inaugural que remete à imagem, conforme pode ser observado no uso do termo na introdução de Über sociale Differenzierung, de Georg Simmel. Ainda, a respeito do conceito de Bildung (e Halbbildung), ver dossiê específico da Revista Espaço Pedagógico, v. 24, n. 3, 2017.

3 Publicação da Georg Simmel Gesellschaft, disponível na plataforma Érudit desde 2017. O dossiê Simmel as Educator está disponível em: https://www.erudit.org/en/journals/sst/2019-v23-n1-sst04800/.

4 Para o sucesso e popularidade das aulas de Simmel, consultar a obra de Waizbort (2013, p. 571 ss.), em especial o capítulo "A cátedra, os gestos e a memória dos que viram e ouviram", onde são reproduzidos depoimentos de época sobre a impressão que Simmel causava aos seus alunos em sala de aula.

5 O termo em alemão entre parêntesis está presente na citação original. Conforme indicado em nota anterior, quando não se tratar de citação literal, o termo Wechselwirkung será vertido como "interação".

${ }^{6}$ A questão da sociabilidade (Geselligkeit), embora importante na obra de Simmel, especialmente no tocante à autonomização dos conteúdos, conforme Questões fundamentais da sociologia (SIMMEL, 2006, p. 59 e ss.), não será discutida à miúde neste texto. Porém, vale apontar ser este também um tema merecedor de atenção, especialmente se for considerado que seus desdobramentos implicam na reflexão crítica sobre o campo da educação e da formação (Bildung), e das relações de poder envolvidos nesse processo.

7 O termo Modernidade Iluminista é utilizado por D'Andrea a partir de obra citada de Louis Dumont (1991 apud D'ANDREA, 2019).

\section{Referências}

AMAT, Matthieu; D'ANDREA, Fabio. Introduction. Simmel Studies, v. 23, n. 1, p. 09-23, 2019. Disponível em: https:/www.erudit.org/en/journals/sst/2019-v23-n1-sst04800/1062536ar/. Acesso em: 03 jun. 2020. DOI: https://doi.org/10.7202/1062536ar.

BERGER, Peter L.; LUCKMANN, Thomas. A construção social da realidade: tratado de sociologia do conhecimento. Petrópolis: Vozes, 1985.

BRASIL. Constituição (1988). Constituição da República Federativa do Brasil. Brasília, DF: Senado Federal, 1988. Disponível em: http://www.planalto.gov.br/ccivil_03/constituicao/constituicao.htm. Acesso em: 07 jun. 2020.

D'ANDREA, Fabio. Simmel: Bildung as the Form of Subjectivity. Simmel Studies, v. 23, n. 1, p. 43-66, 2019. Disponível em: https:/www.erudit.org/en/journals/sst/2019-v23-n1-sst04800/1062538ar/. Acesso em: 03 jun. 2020. DOI: https://doi.org/10.7202/1062538ar.

FREIRE, Paulo. Pedagogia da autonomia: saberes necessários à prática educativa. Rio de Janeiro: Paz e Terra, 2020.

GOLDMAN, Marina Alejandra. La educación como Puente: Simmel, la tragedia de la cultura, y el desarrollo significativo del ser. Enfoques, Libertador San Martin, XXV, 1, Otoño 2013, p. 2538. Disponível em: http://publicaciones.uap.edu.ar/index.php/revistaenfoques/article/view/112. Acesso em: 01 jul. 2020.

GONON, Philipp. Simmel and his Lectures on Education in the Context of German Progressive Education. Simmel Studies, v. 23, n. 1, p. 89-107, 2019. Disponível em: https:/www.erudit.org/ fr/revues/sst/2019-v23-n1-sst04800/1062540ar/. Acesso em: 03 jun. 2020. DOI: https://doi.org/10.7202/1062540ar.

HOOKS, Bell. Ensinando a transgredir: a educação como prática da liberdade. São Paulo: WMF Martins Fontes, 2017.

MAFFESOLI, Michel. A transfiguração do político. Porto Alegre: Sulina, 2011. 
MAFFESOLI, Michel. O paradigma estético (a sociologia como arte). In: SOUZA, Jessé; ÖELZE, Berthold. Simmel e a modernidade. Brasília: Editora Universidade de Brasília, 2014. p. 235-247.

MÜLLER, Hans-Peter. Teaching Life. The education of a Modern Personality. Simmel Studies, v. 23, n. 1, p. 25-42, 2019. Disponível em: https://www.erudit.org/fr/revues/sst/2019-v23-n1-sst04800/1062537ar/. Acesso em: 03 jun. 2020. DOI: https://doi.org/10.7202/1062537ar.

MÜLLER, Hans-Peter; CAVALLI, Alessandro; FERRARA, Alessandro. How Is Individuality Possible? Georg Simmel's Philosophy and Sociology of Individualism. Simmel Studies, v. 22, n. 1, p. 15-43, 2018. Disponível em: https://www.erudit.org/fr/revues/sst/2018-v22-n1-sst03939/1051006ar/. Acesso em: 03 jun. 2020. DOI: https://doi.org/10.7202/1051006ar.

NORDENBO, Sven Erik. Bildung and the Thinkin of Bildung. Journal of Philosophy of Education, v. 36, n. 03, 2002. Disponível em: http://armytage.net/pdsdata/Bildung\%20and\%20the\%20 thinking\%20of\%20bildung.pdf. Acesso em: 11 jun. 2020.

SETTON, Maria da Graça Jacintho. A particularidade do processo de socialização contemporâneo. Tempo Social, São Paulo, v. 17, n. 2, p. 335-350, nov. 2005. Disponível em: http://www.scielo.br/scielo.php?script=sci_arttext\&pid=S0103-20702005000200015\&lng=en\&nrm=iso. Acesso em: 11 jun. 2020.

SETTON, Maria da Graça Jacintho; OLIVEIRA, Mirtes Marins de. Os museus como espaços educativos. Educação em Revista, Belo Horizonte, n. 33, e162678, 2017.

SIMMEL, Georg. A crise da cultura. In: SIMMEL, Georg. O conflito da cultura moderna e outros escritos. São Paulo: Editora Senac São Paulo, 2013. p. 101-117.

SIMMEL, Georg. Georg Simmel arte e vida: ensaios de estética e sociologia. São Paulo: Hucitec, 2016.

SIMMEL, Georg. O conceito e a tragédia da cultura. In: SOUZA, Jessé; ÖELZE, Berthold. Simmel e a modernidade. Brasília: Editora Universidade de Brasília, 2014. p. 77-105.

SIMMEL, Georg. Questões fundamentais da sociologia. Rio de Janeiro: Zahar, 2006.

VANDENBERGHE, Frédéric. As sociologias de Georg Simmel. Petrópolis: Vozes, 2018.

VERNIK, Esteban. Prefácio a ‘Sobre la diferenciación social' de Georg Simmel. In: SIMMEL, Georg. Sobre la diferenciación social: investigaciones sociológicas y psicológicas, Barcelona: Editorial Gedisa, 2017. E-book.

VERNIK, Esteban. What Is a Class? On the Simmelian Art of Learning and Teaching. Simmel Studies, v. 23, n. 1, p. 67-87, 2019. Disponível em: https://www.erudit.org/fr/revues/sst/2019-v23-n1-sst04800/1062539ar/. Acesso em: 03 jun. 2020. DOI: https://doi.org/10.7202/1062539ar.

WAIZBORT, Leopoldo. As aventuras de Georg Simmel. São Paulo: Programa de Pós-Graduação em Sociologia da FFLCH-USP; Editora 34, 2013.

WEBER, Max. Burocracia. In: WEBER, Max. Ensaios de sociologia. Rio de Janeiro: Guanabara Koogan, 1979. p. 229-282. 